T. WATANABE

KODAI MATH. J.

15 (1992), 82-101

\title{
SUFFICIENT CONDITIONS FOR UNIMODALITY OF NON-SYMMETRIC LÉVY PROCESSES
}

\author{
By TOSHIRo WATANABE
}

\section{Introduction and results.}

A measure $\mu$ on $R^{1}$ is said to be unimodal with mode $a$ if $\mu(d x)=c \delta_{a}(d x)$ $+f(x) d x$, where $c \geqq 0, \delta_{a}$ is the delta measure at $a, f(x)$ is non-decreasing for $x<a$ and non-increasing for $x>a$. A probability measure $\mu$ on $R^{1}$ is said to be strongly unimodal if, for every unimodal probability measure $\eta$, the convolution $\mu * \eta$ is unimodal. Let $\left\{X_{t}\right\}(t \geqq 0)$ be a Lévy process on $R^{\mathbf{1}}$ (that is a process with stationary independent increments starting at the origin). The process $\left\{X_{t}\right\}$ is said to be of class $L$ if the distribution $\mu_{t}$ of $X_{t}$ is of class $L$ for every $t>0$ (equivalently, for some $t>0$ ). A necessary and sufficient condition for an infinitely divisible distribution $\mu$ with Lévy measure $\nu$ to be of class $L$ is that $|x| \nu(d x)$ is unimodal with mode 0 . The process $\left\{X_{t}\right\}$ is said to be unimodal if the distribution $\mu_{t}$ is unimodal for every $t>0$. Medgyessy [1] and Wolfe [13] show that symmetric Lévy processes are unimodal if and only if their Lévy measures are unimodal with mode 0 . Yamazato [14] proves that every process of class $L$ is unimodal. Watanabe [8] shows that there exist unimodal non-symmetric Lévy processes that are not of class $L$. Also, Watanabe [10] gives a necessary and sufficient condition for unimodality of one-sided Lévy processes by using zeros of some polynomials. However it has not been successful to find a necessary and sufficient condition in terms of their Lévy measures. Other results on the unimodality of Lévy processes are obtained by Sato [2,3], Sato-Yamazato [4], Steutel-van Harn [6], Watanabe [9, 11], Wolfe [12], and Yamazato [15]. The purpose of this paper is to improve the previous paper [8] and to give sufficient conditions for unimodality of nonsymmetric Lévy processes that are not of class $L$, in terms of their Lévy measures. To describe our results, we need to introduce some notations.

From now on, let $n$ be a positive integer,

$$
0=b_{0}<a_{1}<b_{1}<a_{2}<b_{2}<\cdots<a_{n}<b_{n}<a_{n+1} \leqq \infty,
$$

and let $k(x)$ be a function on $(0, \infty)$ such that $k(0+)<\infty, k(x)>0$ on $\left(0, a_{n+1}\right)$, $k(x)=0$ on $\left[a_{n+1}, \infty\right), k(x)$ is non-increasing on $\left[b_{m}, a_{m+1}\right](0 \leqq m \leqq n)$, non-

Received May 13, 1991. 
decreasing and concave on $\left(a_{m}, b_{m}\right)(1 \leqq m \leqq n)$, and $\int_{0}^{\infty}(1+x)^{-1} k(x) d x<\infty$. Let $E=\bigcup_{m=1}^{n}\left(a_{m}, b_{m}\right)$. Let

$$
\begin{aligned}
& d_{m}=k\left(a_{m}-\right)-k\left(a_{m}+\right)>0, \\
& e_{m}=k\left(b_{m}-\right)-k\left(b_{m}+\right)>0, \\
& h_{m}=k\left(b_{m}-\right)-k\left(a_{m}+\right)>0, \\
& \delta_{m}=k^{*}\left(a_{m}+\right)<\infty,
\end{aligned}
$$

for $1 \leqq m \leqq n$, and

$$
K(x)=\int_{0}^{x}(k(0+)-k(u)) u^{-1} d u<\infty
$$

for $0<x<\infty$, where $k^{*}(x)$ is the Radon-Nikodym derivative of $k(x)$ on $E$.

Our results are as follows.

THEOREM 1.1. Let $\left\{X_{t}\right\}$ be a one-sided Lévy process without drift such that

$$
\begin{aligned}
& E \exp \left(-z X_{t}\right)=\exp (t \phi(z)), \\
& \phi(z)=\int_{0}^{\infty}\left(e^{-z x}-1\right) x^{-1} k(x) d x
\end{aligned}
$$

for $z \geqq 0$. Then $\left\{X_{t}\right\}$ is unimodal if the following additional conditions are satisfied:

(H.1) $\quad k(0+) \leqq 2$.

(H.2) $k(x)=g(x)+h(x)$, where $g(x)$ and $h(x)$ are nonnegative on $(0, \infty)$, $g(0+) \geqq 1$, the set $\{x: g(x)>0\}$ is an interval, $\log g(x)$ is concave on this interval, and $h(x)$ is non-increasing on $(0, \infty)$.

(H.3) There exists a real number $\alpha$ snch that $0<\alpha<a_{1}$, and, for every $m$ $(1 \leqq m \leqq n)$,

(H.3.a) $\alpha\left(e_{m}-h_{m}\right) \geqq e_{m}\left(b_{m}-a_{m}\right)$,

(H.3.b) $(k(\alpha-)-K(\alpha)) d_{m}>k(\alpha-) h_{m}$,

(H.3.c) $\left(k(\alpha-)-k\left(b_{m}-\right)\right) d_{m} \geqq \delta_{m}\left(k(\alpha-) a_{m}+\alpha k\left(b_{m}-\right)\right)$.

Remark 1.1. Assume that

(H.4) $\log k(x)$ is concave on $\left(\beta, a_{n+1}\right)$ for some $\beta$ satisfying $b_{n} \leqq \beta \leqq a_{n+1}$.

In this case, we can define a function $g(x)$ on $(0, \infty)$ such that $g(x)$ is absolutely continuous on $\left(0, a_{n+1}\right)$ and

$$
g^{*}(x)=\sup _{x \leqq y \in E} k^{*}(y), \quad \text { for } 0<x<b_{n},
$$

if $\beta<a_{n+1}$,

$$
g(x)=k(\beta+), \quad \text { for } \quad b_{n} \leqq x \leqq \beta,
$$


if $\beta=a_{n+1}$,

$$
=k(x), \quad \text { for } \quad \beta<x<\infty \text {, }
$$

$$
\begin{array}{ll}
g(x)=k(\beta-) & \text { for } \quad b_{n} \leqq x<\beta, \\
g(x)=0 & \text { for } \quad x \geqq \beta,
\end{array}
$$

where $k^{*}(y)$ and $g^{*}(x)$ are the Radon-Nikodym derivatives of $k(y)$ and $g(x)$, respectively. Then (H.2) is satisfied for this $g(x)$ if $g(0+) \geqq 1$.

Remark 1.2. It should be noted that $g(x)$ in (H.2) is positive and nondecreasing on $\left(0, b_{n}\right)$. Hence $k(x) \geqq g(x) \geqq g(0+) \geqq 1$ for $0<x<b_{n}$ and $d_{m} \leqq k(0+)$ $-g(0+) \leqq 1$ for $1 \leqq m \leqq n$ by (H.1) and (H.2). Also we note that, for every

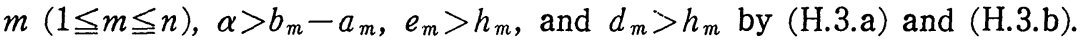

Combining the above theorem with Corollary 1.2 of Watanabe [11], we obtain the following result.

COROLLARY 1.1. Let $k^{(1)}(x)$ and $k^{(2)}(x)$ be two functions satisfying the conditions for $k(x)$ and let $\left\{X_{t}^{(1)}\right\}$ and $\left\{X_{t}^{(2)}\right\}$ be independent unimodal one-sided Lévy processes in Theorem 1.1 associated with $k^{(1)}(x)$ and $k^{(2)}(x)$, respectively. Let $a, b, \sigma$ be nonnegative, $\gamma \in R^{1}$, and $\{B(t)\}$ be a Brownian motion independent of $\left\{X_{t}^{(1)}\right\}$ and $\left\{X_{t}^{(2)}\right\}$. Then the process $X_{t}=X_{a t}^{(1)}-X_{b t}^{(2)}+\sigma B(t)+\gamma t$ is unimodal.

In order to prove Theorem 1.1, we show in Section 2 integro-differential equations and fundamental inequalities satisfied by the density function of the process. In Section 3 we prove Theorem 1.1.

\section{Preliminaries.}

In this section, let $\left\{X_{t}\right\}$ be a one-sided Lévy process satisfying (1.2) with $k(x)$ described in the paragraph preceding Theorem 1.1.

Assume that

(S.1) $k(x)$ is a step function on $\left[b_{m}, a_{m+1}\right]$ for $0 \leqq m \leqq n$.

(S.2) $\quad b_{m}-a_{m} \leqq \alpha<a_{1}, e_{m}>h_{m}$, and $d_{m}>h_{m}$ for $1 \leqq m \leqq n$.

Remark 2.1. The condition (S.2) implies that $k(u) \geqq k\left(a_{m}-\right.$ ) for $0<u<a_{m}$ for $1 \leqq m \leqq n$.

Let $\left\{c_{j}: 0 \leqq j \leqq N+1\right\}$ be the union of $\left\{b_{j}: 0 \leqq j \leqq n\right\},\left\{a_{j}: 1 \leqq j \leqq n+1\right\}$ and the set of jumping points of $k(x)$ in $\left(b_{m}, a_{m+1}\right)$ for $0 \leqq m \leqq n$. They are numbered so that

$$
0=c_{0}<c_{1}<c_{2}<\cdots<c_{N-1}<c_{N}=a_{n+1} \leqq c_{N+1}=\infty .
$$

Let $c_{j(m)}=a_{m}$ and $c_{j(m)+1}=b_{m}$ for $1 \leqq m \leqq n$. Define

and

$$
J_{1}=\{j: 0 \leqq j \leqq N \text { and } j \neq j(m) \text { for } 1 \leqq m \leqq n\}
$$




$$
J_{2}=\{j: 1 \leqq j \leqq N \text { and } j \neq j(m), j(m)+1 \text { for } 1 \leqq m \leqq n\} .
$$

Define $p_{j}=k\left(c_{j}-\right)-k\left(c_{j}+\right)$ for $j \in J_{2}$, understanding $p_{N}=0$ if $c_{N}=\infty$ and $p_{N}>0$ if $c_{N}<\infty$. Define $p_{\jmath}=0$ for $j \in J_{2}^{c}$. The distribution $\mu_{t}$ of $X_{t}$ is absolutely continuous for every $t>0$ by Tucker [7], since $\int_{0}^{1} u^{-1} k(u) d u=\infty$. Let $f(x)$ be the density function of $\mu_{t}$. We do not write dependence of $f(x)$ on $t$ explicitely.

LEMMA 2.1. For $t>0$, we have

$$
\begin{aligned}
x f(x)= & t \int_{0}^{x} f(x-u) k(u) d u \\
= & t \lambda F(x)-t \sum_{j=1}^{N} p_{j} F\left(x-c_{\jmath}\right) \\
& +t \sum_{m=1}^{n}\left\{-d_{m} F\left(x-a_{m}\right)-e_{m} F\left(x-b_{m}\right)+\int_{E_{m}} F(x-u) k^{*}(u) d u\right\}
\end{aligned}
$$

for $x \neq 0$, where $\lambda=k(0+), F(x)=\int_{-\infty}^{x} f(u) d u$, and $E_{m}=\left(a_{m}, b_{m}\right)$ for $1 \leqq m \leqq n$.

Proof. The identity (2.1) follows from Steutel [5] and integration by parts.

Remark 2.2. We see from (2.1) that $f(x)=0$ for $x<0, f(x)>0$ for $x>0$, and $f(x)$ is continuous for $x>0$.

LEMMA 2.2. For $t>0$, we have

$$
\begin{aligned}
x f^{\prime}(x)= & (\lambda t-1) f(x)-t \sum_{j=1}^{v} p_{\jmath} f\left(x-c_{\jmath}\right) \\
& +t \sum_{m=1}^{n}\left\{-d_{m} f\left(x-a_{m}\right)-e_{m} f\left(x-b_{m}\right)+\int_{E_{m}} f(x-u) k^{*}(u) d u\right\}
\end{aligned}
$$

for $x \neq c,(0 \leqq j \leqq N)$.

Proof. Since $f(x)$ is continuous for $x>0, F(x-c$,$) is differentiable for$ $x \neq c$. Because $f(x)$ is integrable on $(-\infty, \infty)$ and $k^{*}(u) \leqq \delta_{m}<\infty$ on $E_{m}$, $\int_{E_{m}} f(x-u) k^{*}(u) d u$ is continuous in $x$. We get

$$
\begin{aligned}
\frac{d}{d x} \int_{E_{m}} F(x-u) k^{*}(u) d u & =\lim _{h \rightarrow 0} h^{-1} \int_{x}^{x+h} d y \int_{E_{m}} f(y-u) k^{*}(u) d u \\
& =\int_{E_{m}} f(x-u) k^{*}(u) d u
\end{aligned}
$$

for $-\infty<x<\infty$ for $1 \leqq m \leqq n$. Hence, differentiating (2.1), we obtain (2.2). 
LEMMA 2.3. For $t>0$, we have

$$
\begin{aligned}
& f(x)=C x^{\lambda t-1}, \\
& f^{\prime}(x)=C(\lambda t-1) x^{\lambda t-2},
\end{aligned}
$$

and

$$
f^{\prime \prime}(x)=C(\lambda t-1)(\lambda t-2) x^{\lambda t-3}
$$

for $0<x<c_{1}$, where $C$ is a positive constant which depends on $t$.

Proof. The identity (2.2) means

$$
f^{\prime}(x)=(\lambda t-1) f(x)
$$

for $0<x<c_{1}$. Hence we obtain (2.4), which implies (2.5) and (2.6).

Remark 2.3. We find from (2.2), (2.4), and Remark 2.2 that, for $t>0$, $f^{\prime}(x)$ is continuous except at $x=c,(0 \leqq j \leqq N)$. Moreover, for $t>\lambda^{-1}, f(x)$ is continuous on $(-\infty, \infty)$ and $f^{\prime}(x)$ is continuous on $(0, \infty)$.

LEMMA 2.4. For $t>\lambda^{-1}$, we have

$$
\begin{aligned}
x f^{\prime \prime}(x)= & (\lambda t-2) f^{\prime}(x)-t \sum_{j=1}^{N} p_{\jmath} f^{\prime}\left(x-c_{j}\right) \\
& +t \sum_{m=1}^{n}\left\{-d_{m} f^{\prime}\left(x-a_{m}\right)-e_{m} f^{\prime}\left(x-b_{m}\right)+\int_{E_{m}} f^{\prime}(x-u) k^{*}(u) d u\right\}
\end{aligned}
$$

for $x \neq c,(0 \leqq j \leqq N)$.

Proof. Since $f^{\prime}(x)$ is integrable on $(0, M)$ for any $M>0, \int_{E_{m}} f(x-u) k^{*}(u) d u$ is differentiable on $(-\infty, \infty)$ for every $m(1 \leqq m \leqq n)$ as in (2.3). Hence, differentiating (2.2), we get (2.8).

LEMMA 2.5. Let $t>0$ and $x \neq c,(0 \leqq j \leqq N)$. Suppose that $f(u)$ is nonincreasing for $0<u<x$.

(i) If $x \in E^{c}=\left(\bigcup_{m=1}^{n} E_{m}\right)^{c}$, then

$$
x f^{\prime}(x) \leqq(k(x-) t-1) f(x) .
$$

(ii) If $x \in E_{q}$ for some $q(1 \leqq q \leqq n)$, then

$$
x f^{\prime}(x)<f(x)\left\{t k\left(a_{q}+\right)-1+\delta_{q}\left(b_{q}-t a_{q} k\left(a_{q}+\right)\right) k\left(a_{q}+\right)^{-1}\right\} .
$$

Proof. We have 


$$
f\left(x-c_{j}\right) \geqq f(x)
$$

for $c_{j}<x$ and

$$
\sum_{b_{m}<x} \int_{E_{m}} f(x-u) k^{*}(u) d u \leqq \sum_{b_{m}<x} f\left(x-b_{m}\right) h_{m} .
$$

Hence, if $x \in E^{c}$, then we obtain from (S.2) and (2.2) that

$$
\begin{aligned}
x f^{\prime}(x) \leqq & \left\{\lambda t-1-t \sum_{c j<x} p_{j}-t \sum_{a} d_{m} d_{m}\right\} f(x) \\
& -t \sum_{b_{m}<x}\left(e_{m}-h_{m}\right) f\left(x-b_{m}\right) \\
\leqq & (k(x-) t-1) f(x),
\end{aligned}
$$

noting that

$$
\lambda-\sum_{j<x} p_{j}-\sum_{a<x} d_{m}-\sum_{b_{m}<x}\left(e_{m}-h_{m}\right)=k(x-) .
$$

Similarly we get

$$
x f^{\prime}(x) \leqq\left(k\left(a_{q}+\right) t-1\right) f(x)+t \int_{E_{q}} f(x-u) k^{*}(u) d u
$$

for $x \in E_{q}$. We have, for $x \in E_{q}$,

$$
\int_{E_{q}} f(x-u) k^{*}(u) d u \leqq \delta_{q} \int_{0}^{x-a} q f(u) d u .
$$

We obtain from (2.1) and Remark 2.1 that

$$
\begin{aligned}
x f(x) & =t \int_{0}^{x} f(x-u) k(u) d u \\
& \geqq t k\left(a_{q}+\right) \int_{0}^{x} f(u) d u \\
& \geqq t k\left(a_{q}+\right) \int_{0}^{x-a_{q}} f(u) d u+t k\left(a_{q}+\right) a_{q} f(x)
\end{aligned}
$$

for $x \in E_{q}$, which implies that

$$
\left(b_{q}-t a_{q} k\left(a_{q}+\right)\right) f(x)>t k\left(a_{q}+\right) \int_{0}^{x-a_{q}} f(u) d u .
$$

Hence (2.10) follows from (2.14), (2.15), and (2.17). Thus we have proved Lemma 2.5 .

LEMMA 2.6. Let $\lambda t>1$. Suppose that $f(u)$ is non-decreasing for $0<u<x$ and non-increasing for $x \leqq u \leqq y$.

(i) If $c_{Q} \leqq x<c_{Q+1}$ for some $Q(0 \leqq Q \leqq N)$, then

$$
x f^{\prime}(x) \geqq\left(k\left(c_{Q}+\right) t-1\right) f(x) .
$$


(ii) If $a_{q} \leqq x<b_{q}$ for some $q(1 \leqq q \leqq n)$ and $y<a_{q}+\alpha$, then

$$
y f^{\prime}(y) \leqq(k((y-x)+) t-1) f(y)-t\left(k((y-x)+)-k\left(b_{q}-\right)\right) f\left(y-a_{q}\right) .
$$

Proof of (i). We have

$$
f(x-c) \leqq f(x)
$$

for $c, \leqq x$ and

$$
\sum_{b_{m} \leq x} \int_{E_{m}} f(x-u) k^{*}(u) d u \geqq \sum_{b_{m} \leq x} f\left(x-b_{m}\right) h_{m} .
$$

Hence we obtain from (S.2) and (2.2) that

$$
\begin{aligned}
x f^{\prime}(x) & \geqq\left(\lambda t-1-t \sum_{c_{j} \leq x} p_{j}-t \sum_{a_{m} \leq x} d_{m}\right) f(x)-t \sum_{b_{m} \leq x}\left(e_{m}-h_{m}\right) f\left(x-b_{m}\right) \\
& \geqq\left(k\left(c_{Q}+\right) t-1\right) f(x),
\end{aligned}
$$

noting that $\lambda-\sum_{c j \leq x} p_{j}-\sum_{a_{m} \leq x} d_{m}-\sum_{b_{m} \leq x}\left(e_{m}-h_{m}\right)=k\left(c_{Q}+\right)$. Thus we have proved (i).

Proof of (ii). Let $R$ be such that $y-c_{R+1}<x \leqq y-c_{R}$ with $0 \leqq R<j(1)$. As in the proof of (i), we get

$$
f\left(y-c_{j}\right) \geqq f(y)
$$

for $0 \leqq j \leqq R$ and

$$
f\left(y-c_{\jmath}\right) \geqq f\left(y-a_{q}\right)
$$

for $R+1 \leqq j \leqq j(q)$. We have

$$
\int_{E_{m}} f(y-u) k^{*}(u) d u \leqq f\left(y-a_{m}\right) h_{m}
$$

for $1 \leqq m \leqq n$, noting that $y-a_{m}<a_{q} \leqq x$ for $1 \leqq m \leqq n$. Hence we obtain from (S.2) and (2.2) that

$$
\begin{aligned}
y f^{\prime}(y) \leqq & \left.t\left(\lambda-\sum_{j=1}^{R} p_{j}\right)-1\right\} f(y)-t\left(\sum_{j=R+1}^{j(q)} p_{j}+\sum_{m=1}^{q-1} e_{m}\right) f\left(y-a_{q}\right) \\
& -t \sum_{m=1}^{n}\left(d_{m}-h_{m}\right) f\left(y-a_{m}\right) \\
\leqq & (k((y-x)+) t-1) f(y)-t\left(k((y-x)+)-k\left(b_{q}-\right)\right) f\left(y-a_{q}\right),
\end{aligned}
$$

noting that $\sum_{j=R+1}^{j(q)} p_{j}+\sum_{m=1}^{q-1} e_{m}+\sum_{m=1}^{q}\left(d_{m}-h_{m}\right)=k((y-x)+)-k\left(b_{q}-\right)$ and $\lambda-\sum_{j=1}^{R} p_{j}=$ $k((y-x)+)$. Thus we have proved Lemma 2.6.

When $1<\lambda t<2$, define 


$$
\begin{gathered}
S=\{x: x>0 \text { and } f \text { attains local maximum at } x\}, \\
T=\left\{x: x>0, x \neq c,(0 \leqq j \leqq N), \text { and } f^{\prime \prime}(x) \geqq 0\right\},
\end{gathered}
$$

and

$$
\inf S=s_{0} \text { and } \inf T=y .
$$

Obviously the set $S$ is non-empty. The set $T$ is also non-empty, because the support of $\mu_{t}$ is unbounded. We find from (2.5) and (2.6) that

$$
s_{0}>c_{1} \text { and } y \geqq c_{1} \text {. }
$$

LEMMA 2.7. Let $1<\lambda t<2$ and, in addition to (S.1) and (S.2), suppose (H.3.c). Then we have

$$
y \geqq s_{0} \text {. }
$$

Proof. Suppose that $y<s_{0}$. We shall consider three possible cases and show that absurdity occurs in each case.

Case 1. $y<s_{0}$ and $y=c_{Q}(1 \leqq Q \leqq N)$. There exists a sequence $y_{k}$ such that $y<y_{k}<s_{0}, f^{\prime \prime}\left(y_{k}\right) \geqq 0$, and $y_{k} \rightarrow y$ as $k \rightarrow \infty$. Since $f^{\prime}\left(y_{k}-u\right) \geqq 0$ for $0<u<y_{k}$, we get

$$
\int_{E_{m}} f^{\prime}\left(y_{k}-u\right) k^{*}(u) d u \leqq \delta_{m}\left(f\left(y_{k}-a_{m}\right)-f\left(y_{k}-b_{m}\right)\right)
$$

for $1 \leqq m \leqq n$. Since, as $k \rightarrow \infty, f^{\prime}\left(y_{k}\right) \rightarrow f^{\prime}(y) \geqq 0$,

$$
\begin{array}{ll}
f^{\prime}\left(y_{k}-c_{\jmath}\right) \longrightarrow f^{\prime}\left(y-c_{\jmath}\right)>0 & \text { for } 1 \leqq j \leqq Q-1, f^{\prime}\left(y_{k}-c_{Q}\right) \rightarrow f^{\prime}(0+)=\infty, \\
f^{\prime}\left(y_{k}-c_{j}\right) \longrightarrow f^{\prime}\left(y-c_{j}\right)=0 & \text { for } j \geqq Q+1, \text { and } f\left(y_{k}-c_{j}\right) \rightarrow f\left(y-c_{\jmath}\right)
\end{array}
$$

for $0 \leqq j \leqq N$, we obtain from (2.8) and (2.32) that

$$
\begin{aligned}
0 \leqq & y_{k} f^{\prime \prime}\left(y_{k}\right) \leqq(\lambda t-2) f^{\prime}\left(y_{k}\right)-t \sum_{\jmath=1}^{N} p_{\jmath} f^{\prime}\left(y_{k}-c_{\jmath}\right) \\
& +t \sum_{m=1}^{n}\left\{-d_{m} f^{\prime}\left(y_{k}-a_{m}\right)-e_{m} f^{\prime}\left(y_{k}-b_{m}\right)+\delta_{m}\left(f\left(y_{k}-a_{m}\right)-f\left(y_{k}-b_{m}\right)\right)\right\} \\
& \longrightarrow-\infty
\end{aligned}
$$

as $k \rightarrow \infty$. This is a contradiction.

Case 2. $y<s_{0}$ and $c_{Q}<y<c_{Q+1}$ with $Q \in J_{1}$. Since $f^{\prime}(y) \geqq 0, f^{\prime}\left(y-c_{j}\right)>0$ for $1 \leqq j \leqq Q$, and $f^{\prime}(y-u)<f^{\prime}\left(y-b_{m}\right)$ for $u \in E_{m}(j(m)<Q)$, we have by $(2.8)$

$$
\begin{aligned}
0 \leqq & y f^{\prime \prime}(y) \leqq(\lambda t-2) f^{\prime}(y)-t \sum_{j=1}^{Q} p_{\jmath} f^{\prime}\left(y-c_{j}\right) \\
& +t \sum_{\jmath(m)<Q}\left\{-d_{m} f^{\prime}\left(y-a_{m}\right)-\left(e_{m}-h_{m}\right) f^{\prime}\left(y-b_{m}\right)\right\}<0 .
\end{aligned}
$$


This is a contradiction.

Case 3. $y<s_{0}$ and $a_{q}<y<b_{q}(1 \leqq q \leqq n)$. We shall first prove that

$$
d_{q} f^{\prime}\left(y-a_{q}\right)>\delta_{q} f\left(y-a_{q}\right) .
$$

We get by (i) of Lemma 2.6 that

$$
\begin{aligned}
\alpha f^{\prime}\left(y-a_{q}\right) & \geqq\left(y-a_{q}\right) f^{\prime}\left(y-a_{q}\right) \\
& \geqq\left(k\left(\left(y-a_{q}\right)+\right) t-1\right) f\left(y-a_{q}\right) \\
& \geqq(k(\alpha-) t-1) f\left(y-a_{q}\right),
\end{aligned}
$$

noting that $y-a_{q}<\alpha<a_{1}$ by (S.2). We obtain from (ii) of Lemma 2.6 with $y=x$ and from $f(y) \leqq f\left(y-a_{q}\right)+f^{\prime}\left(y-a_{q}\right) a_{q}$ that

$$
\begin{array}{r}
0 \leqq y f^{\prime}(y) \leqq(\lambda t-1) f(y)-t\left(\lambda-k\left(b_{q}-\right)\right) f\left(y-a_{q}\right) \\
\leqq\left(t k\left(b_{q}-\right)-1\right) f\left(y-a_{q}\right)+(\lambda t-1) f^{\prime}\left(y-a_{q}\right) a_{q},
\end{array}
$$

and hence

$$
\left(-t k\left(b_{q}-\right)+1\right) f\left(y-a_{q}\right)<f^{\prime}\left(y-a_{q}\right) a_{q},
$$

noting that $\lambda t-1<1$. The identity (2.36) shows that (2.35) holds for $t>T_{1}$ and the identity (2.38) implies that (2.35) holds for $t \leqq T_{2}$, where

and

$$
T_{1}=d_{q}^{-1} k(\alpha-)^{-1}\left(\delta_{q} \alpha+d_{q}\right)
$$

$$
T_{2}=d_{q}^{-1} k\left(b_{q}-\right)^{-1}\left(d_{q}-\delta_{q} a_{q}\right) .
$$

Hence it is sufficient for (2.35) that $T_{2} \geqq T_{1}$, which follows from (H.3.c). In fact, we have by (H.3.c)

(2.39) $\quad T_{2}-T_{1}$

$$
\begin{aligned}
& =d_{q}^{-1} k\left(b_{q}-\right)^{-1} k(\alpha-)^{-1}\left\{\left(k(\alpha-)-k\left(b_{q}-\right)\right) d_{q}-\delta_{q}\left(a_{q} k(\alpha-)+\alpha k\left(b_{q}-\right)\right)\right\} \\
& \geqq 0 .
\end{aligned}
$$

Since $\int_{E_{q}} f^{\prime}(y-u) k^{*}(u) d u \leqq \delta_{q} f\left(y-a_{q}\right)$ and $\int_{E_{m}} f^{\prime}(y-u) k^{*}(u) d u<h_{m} f^{\prime}\left(y-b_{m}\right)$ for $1 \leqq m \leqq q-1$, we obtain from (2.8) and (2.35) that

$$
\begin{aligned}
0 \leqq & y f^{\prime \prime}(y) \leqq(\lambda t-2) f^{\prime}(y)-t \sum_{j=1}^{j(q)} p_{j} f^{\prime}\left(y-c_{j}\right) \\
& +t \sum_{m=1}^{q-1}\left\{-d_{m} f^{\prime}\left(y-a_{m}\right)-\left(e_{m}-h_{m}\right) f^{\prime}\left(y-b_{m}\right)\right\} \\
& -t\left\{d_{q} f^{\prime}\left(y-a_{q}\right)-\delta_{q} f\left(y-a_{q}\right)\right\}<0 .
\end{aligned}
$$


This is a contradiction. Thus we have proved Lemma 2.7 .

\section{Proof of Theorem 1.1.}

Let $\left\{X_{t}\right\}$ be a one-sided Lévy process satisfying (1.2). Let $\mu_{t}$ be the distribution of $X_{t}$.

Proposition 3.1. Let $\lambda t \leqq 1$. Suppose (S.2) and that, for every $m(1 \leqq m \leqq n)$,

(S.3.a) $k\left(a_{m}+\right) \geqq \delta_{m} a_{m}$,

(S.3.b) $\quad k\left(a_{m}+\right)\left(\lambda-k\left(a_{m}+\right)\right) \geqq \boldsymbol{\delta}_{m}\left(\lambda b_{m}-k\left(a_{m}+\right) a_{m}\right)$.

Then $\mu_{t}$ is unimodal with mode 0 .

Proof. We divide the proof into two steps.

First step. Suppose (S.1) and continue to use the notation in Section 2 . The identity (2.5) implies that $f^{\prime}(x) \leqq 0$ for $0<x<c_{1}$. We shall prove that $f^{\prime}(x) \leqq 0$ for $0<x \neq c_{\jmath}(1 \leqq j \leqq N)$. Suppose that $f^{\prime}\left(x_{0}\right)>0$ for some $x_{0} \neq c$, $(1 \leqq j \leqq N)$. Let

$$
x_{1}=\inf \left\{x: x>0, x \neq c,(1 \leqq j \leqq N) \text {, and } f^{\prime}(x)>0\right\} .
$$

Then we note that $c_{1} \leqq x_{1}<x_{0}, f^{\prime}\left(x_{1}+\right) \geqq 0$, and $f^{\prime}(x) \leqq 0$ for $0<x<x_{1}$ except at $x=c,(1 \leqq j \leqq N)$. We shall consider three possible cases and show that absurdity occurs in each case.

Case 1. $c_{Q}<x_{1}<c_{Q+1}$ with $1 \leqq Q \in J_{1}$. We get by (i) of Lemma 2.5 that

$$
0 \leqq x_{1} f^{\prime}\left(x_{1}\right) \leqq\left(k\left(x_{1}\right) t-1\right) f\left(x_{1}\right)<0,
$$

noting that $k\left(x_{1}\right) t-1<\lambda t-1 \leqq 0$. This is a contradiction.

Case 2. $a_{q}<x_{1}<b_{q}$ with $1 \leqq q \leqq n$. We find from (S.3.a), (S.3.b), and from $t \leqq \lambda^{-1}$ that

$$
\begin{aligned}
& t k\left(a_{q}+\right)-1+\delta_{q}\left(b_{q}-t a_{q} k\left(a_{q}+\right)\right) k\left(a_{q}+\right)^{-1} \\
\leqq & \lambda^{-1} k\left(a_{q}+\right)^{-1}\left\{k\left(a_{q}+\right)\left(k\left(a_{q}+\right)-\lambda\right)+\delta_{q}\left(\lambda b_{q}-a_{q} k\left(a_{q}+\right)\right)\right\} \leqq 0 .
\end{aligned}
$$

We obtain from (3.2) and (ii) of Lemma 2.5 that

$$
\begin{aligned}
0 \leqq x_{1} f^{\prime}\left(x_{1}\right) & <f\left(x_{1}\right)\left\{t k\left(a_{q}+\right)-1+\delta_{q}\left(b_{q}-t a_{q} k\left(a_{q}+\right)\right) k\left(a_{q}+\right)^{-1}\right\} \\
& \leqq 0
\end{aligned}
$$

This is a contradiction.

Case 3. $x_{1}=c_{Q}$ with $1 \leqq Q \leqq N$. There exists a sequence $y_{k}$ such that $x_{1}<y_{k}, f^{\prime}\left(y_{k}\right)>0$, and $y_{k}-x_{1}$ as $k \rightarrow \infty$. Hence we can show that contradiction occurs in this case by argument similar to Case 1 . In fact let $y_{k}-x_{1}<c_{1}$. Then we have

$$
f\left(y_{k}-c_{\jmath}\right) \geqq f\left(x_{1}\right)
$$


for $c_{j}<y_{k}(j \geqq 1)$ and

$$
\sum_{b_{m}<y_{k}} \int_{E_{m}} f\left(y_{k}-u\right) k^{*}(u) d u \leqq \sum_{b_{m}<y_{k}} f\left(y_{k}-b_{m}\right) h_{m} .
$$

Hence we get, as in the proof of Lemma 2.5, that

$$
0<y_{k} f^{\prime}\left(y_{k}\right) \leqq(\lambda t-1) f\left(y_{k}\right)-t\left(\lambda-k\left(y_{k}-\right)\right) f\left(x_{1}\right)
$$

if $1 \leqq Q \subseteq J_{1}$, and

$$
\begin{aligned}
0<y_{k} f^{\prime}\left(y_{k}\right) \leqq & (\lambda t-1) f\left(y_{k}\right)-t\left(\lambda-k\left(a_{q}+\right)\right) f\left(x_{1}\right) \\
& +t \int_{E_{q}} f\left(y_{k}-u\right) k^{*}(u) d u
\end{aligned}
$$

if $c_{Q}=a_{q}$ with $1 \leqq q \leqq n$. Letting $k \rightarrow \infty$ in (3.6) and (3.7), we have

$$
0 \leqq\left(k\left(x_{1}+\right) t-1\right) f\left(x_{1}\right)<0 \text {. }
$$

This is a contradiction.

Second step. We can find a sequence of Lévy processes $\left\{X_{t}^{(n)}\right\}$ such that each $\left\{X_{t}^{(n)}\right\}$ satisfies (S.1), (S.2), (S.3.a), and (S.3.b) and the distribution $\mu_{t}^{(n)}$ converges weakly to $\mu_{t}$ as $n \rightarrow \infty$ for every $t>0$. Hence $\mu_{t}$ is unimodal with mode 0 . The proof of Proposition 3.1 is complete.

Proposition 3.2. Let $1<\lambda t<2$. Suppose (H.1), (H.2), and (H.3). Then $\mu_{t}$ is unimodal.

Proof. We first assume (S.1) and continue to use the notation in Section 2. As in the second step in the proof of Proposition 3.1, we can prove general case. Let us suppose that $\mu_{t}(d x)=f(x) d x$ is not unimodal for some $t(1<\lambda t<2)$. Then the set $S$ defined in (2.27) contains at least two points and there are two possible cases:

Case A. $s_{0}$ is an isolated point of $S$.

Case B. $s_{0}$ is a limit point of $S$.

In Case $\mathrm{A}$, let $s_{1}=s_{0}$ and

$$
s_{2}=\inf \left\{x: x>s_{1} \text { and } f \text { attains local minimum at } x\right\} .
$$

Then $c_{1}<s_{1}<s_{2}$ by $(2.30)$ and we have

$$
\text { (A.1) } f^{\prime}\left(s_{1}\right)=f^{\prime}\left(s_{2}\right)=0 \text {, }
$$

and

(A.2) $f(x)$ is strictly increasing for $0<x<s_{1}$ and strictly decreasing for $s_{1}<x<s_{2}$.

In Case B, we can choose, for any $\varepsilon>0, s_{1}$ and $s_{2}$ such that $c_{1}<s_{0}<s_{1}<s_{2}$ $<s_{0}+\varepsilon, f\left(s_{2}\right) \leqq f\left(s_{1}\right)$, and $f(x)$ attains local maximum at $x=s_{1}$ and local minimum at $x=s_{2}$. Hence we get 
(B.1) $f^{\prime}\left(s_{1}\right)=f^{\prime}\left(s_{2}\right)=0$.

We shall prove that

(a) Existence of $s_{1}$ and $s_{2}$ leads to a contradiction.

This will imply the unimodality of $\mu_{t}$.

Consider Case A and let $Q$ and $R$ be such that

(3.9) $\quad c_{Q} \leqq s_{1}<c_{Q+1}$ and $s_{2}-c_{R+1} \leqq s_{1}<s_{2}-c_{R}$ with $1 \leqq Q \leqq N$ and $0 \leqq R \leqq N$.

There are two possible cases: $Q<R$ (Case 1) and $Q \geqq R$ (Case 2). We shall prove that absurdity occurs in each case. Define $I\left(s_{\imath}\right)=s_{\imath} f^{\prime}\left(s_{\imath}\right)$ for $i=1,2$.

Case 1. $Q<R$. We obtain from (2.2) and (A.1) that

$$
0=I\left(s_{2}\right)=\sum_{k=1}^{4} I_{k}\left(s_{2}\right),
$$

where

$$
\begin{aligned}
I_{1}\left(s_{2}\right)= & (\lambda t-1) f\left(s_{2}\right)-t \sum_{\jmath=1}^{Q} p_{j} f\left(s_{2}-c_{\jmath}\right)-t \sum_{\jmath(m) \leqq Q} d_{m} f\left(s_{2}-a_{m}\right) \\
& +t \sum_{\jmath(m)<Q}\left\{-e_{m} f\left(s_{2}-b_{m}\right)+\int_{E_{m}} f\left(s_{2}-u\right) k^{*}(u) d u\right\}, \\
I_{2}\left(s_{2}\right)= & -t \sum_{\jmath=Q+1}^{R} p_{j} f\left(s_{2}-c_{j}\right)-t \sum_{Q<\jmath(m)<R} d_{m} f\left(s_{2}-a_{m}\right) \\
& +t \sum_{Q \leq \jmath(m)<R}^{R}\left\{-e_{m} f\left(s_{2}-b_{m}\right)+\int_{E_{m}} f\left(s_{2}-u\right) k^{*}(u) d u\right\}, \\
I_{3}\left(s_{2}\right)= & -t d_{r} f\left(s_{2}-a_{r}\right)-t e_{r} f\left(s_{2}-b_{r}\right)+t \int_{E_{r}} f\left(s_{2}-u\right) k^{*}(u) d u
\end{aligned}
$$

if $R=j(r)(1 \leqq r \leqq n)\left(I_{3}\left(s_{2}\right)=0\right.$ if $\left.R \in J_{1}\right)$, and

$$
\begin{aligned}
I_{4}\left(s_{2}\right)= & -t \sum_{j=R+1}^{N} p_{\jmath} f\left(s_{2}-c_{\jmath}\right) \\
& +t \sum_{R<j(m)}\left\{-d_{m} f\left(s_{2}-a_{m}\right)-e_{m} f\left(s_{2}-b_{m}\right)+\int_{E_{m}} f\left(s_{2}-u\right) k^{*}(u) d u\right\} .
\end{aligned}
$$

We shall prove that

$$
0=I\left(s_{1}\right) \geqq\left(k\left(c_{Q}+\right) t-1\right) f\left(s_{1}\right)
$$

and

$$
0=I\left(s_{2}\right)<\left(k\left(c_{Q}+\right) t-1\right) f\left(s_{2}\right),
$$

which will lead to a contradiction. The inequality (3.15) follows from (2.18) in Lemma 2.6. By argument similar to (2.9), we get 


$$
I_{1}\left(s_{2}\right)<\left(k\left(c_{Q}+\right) t-1\right) f\left(s_{2}\right) .
$$

Since $f\left(s_{2}-u\right) \leqq f\left(s_{2}-b_{m}\right)$ for $u \in E_{m}(j(m)<R)$, we have

$$
\begin{gathered}
I_{2}\left(s_{2}\right) \leqq-t \sum_{j=Q+1}^{R} p_{j} f\left(s_{2}-c_{j}\right)-t \sum_{Q<j(m)<R} d_{m} f\left(s_{2}-a_{m}\right) \\
-t \sum_{Q \leq j(m)<R}\left(e_{m}-h_{m}\right) f\left(s_{2}-b_{m}\right) \leqq 0 .
\end{gathered}
$$

We shall show that, if $R=j(r)(1 \leqq r \leqq n)$, then

$$
I_{3}\left(s_{2}\right) \leqq 0 \text {. }
$$

There are two cases.

(i) Suppose that $s_{2}-a_{r} \geqq \alpha$. Then we get by (H.3.a) that

$$
\begin{aligned}
s_{1} h_{r}-e_{r}\left(s_{2}-b_{r}\right) & <\left(s_{2}-a_{r}\right) h_{r}-e_{r}\left(s_{2}-b_{r}\right) \\
& =\left(s_{2}-a_{r}\right)\left(h_{r}-e_{r}\right)+e_{r}\left(b_{r}-a_{r}\right) \\
& \leqq \alpha\left(h_{r}-e_{r}\right)+e_{r}\left(b_{r}-a_{r}\right) \leqq 0
\end{aligned}
$$

and $s_{2}-b_{r}>0$. We have $f\left(s_{1}\right) / s_{1} \leqq f\left(s_{2}-b_{r}\right) /\left(s_{2}-b_{r}\right)$ by Lemma 2.7. Hence

$$
\begin{gathered}
\int_{E_{r}} f\left(s_{2}-u\right) k^{*}(u) d u-e_{r} f\left(s_{2}-b_{r}\right)<f\left(s_{1}\right) h_{r}-e_{r} f\left(s_{2}-b_{r}\right) \\
\leqq \frac{f\left(s_{2}-b_{r}\right)}{s_{2}-b_{r}}\left\{s_{1} h_{r}-e_{r}\left(s_{2}-b_{r}\right)\right\} \leqq 0
\end{gathered}
$$

by (3.20). Therefore, (3.19) follows from (3.13) in this case.

(ii) Suppose that $s_{2}-a_{r}<\alpha$. Then we note that $s_{1}<s_{2}-a_{r}<\alpha<a_{1}<s_{2}$. Hence we have by (A.2)

$$
f\left(s_{2}-a_{r}\right)>f(\alpha)
$$

It follows from (2.2) that

$$
\begin{aligned}
& x f^{\prime}(x) \geqq(\lambda t-1) f(x)+t f\left(s_{1}\right)(k(x-)-\lambda) \\
&>t f\left(s_{1}\right)(k(x-)-\lambda)
\end{aligned}
$$

for $s_{1}<x<\alpha$. Hence we have

$$
f\left(s_{1}\right)-f(\alpha)<t f\left(s_{1}\right) \int_{0}^{\alpha} x^{-1}(\lambda-k(x-)) d x,
$$

equivalently,

$$
f(\alpha)>(1-t K(\alpha)) f\left(s_{1}\right) .
$$

We obtain from (3.22), (3.25), and (H.3.b) that 


$$
\begin{gathered}
\int_{E_{r}} f\left(s_{2}-u\right) k^{*}(u) d u-d_{r} f\left(s_{2}-a_{r}\right)<f\left(s_{1}\right) h_{r}-d_{r} f(\alpha) \\
<f\left(s_{1}\right)\left\{h_{r}-\left(1-k(\alpha-)^{-1} K(\alpha)\right) d_{r}\right\} \leqq 0,
\end{gathered}
$$

noting that $t \leqq k\left(c_{Q}+\right)^{-1} \leqq k(\alpha)^{-1}$ from (3.15) and from $c_{Q}<\alpha<a_{1}$. Therefore, (3.19) follows from (3.13) and (3.26) in this case. Thus we have proved (3.19). Since $f\left(s_{2}-u\right) \leqq f\left(s_{2}-a_{m}\right)$ for $u \in E_{m}(j(m)>R)$, we find

$$
\begin{gathered}
\sum_{R<j(m)}\left\{\int_{E_{m}} f\left(s_{2}-u\right) k^{*}(u) d u-d_{m} f\left(s_{2}-a_{m}\right)\right\} \\
\leqq \\
\sum_{R<j(m)}\left(h_{m}-d_{m}\right) f\left(s_{2}-a_{m}\right) \leqq 0
\end{gathered}
$$

which shows

$$
I_{4}\left(s_{2}\right) \leqq 0 \text {. }
$$

Hence (3.16) follows from (3.17), (3.18), (3.19), and (3.28). Thus the proof of the assertion (a) in Case 1 is complete.

Case 2. $R \leqq Q$. We obtain from (2.2) and (A.1) that, for $i=1,2$.

$$
0=I\left(s_{\imath}\right)=\sum_{k=1}^{5} I_{k}\left(s_{\imath}\right) \text {, }
$$

where

$$
\begin{aligned}
I_{1}\left(s_{\imath}\right)= & (\lambda t-1) f\left(s_{\imath}\right)-t \sum_{\jmath=1}^{R} p_{\jmath} f\left(s_{i}-c_{\jmath}\right)-t \sum_{\jmath(m) \leqq R} d_{m} f\left(s_{i}-a_{m}\right) \\
& +t \sum_{\jmath(m)<R}\left\{-e_{m} f\left(s_{i}-b_{m}\right)+\int_{E_{m}} f\left(s_{i}-u\right) k^{*}(u) d u\right\}, \\
I_{2}\left(s_{\imath}\right)= & t \int_{E_{r}} f\left(s_{i}-u\right) k^{*}(u) d u-t e_{r} f\left(s_{i}-b_{r}\right)
\end{aligned}
$$

if $R=j(r)(1 \leqq r \leqq n)\left(I_{2}\left(s_{\imath}\right)=0\right.$ if $\left.R \in J_{1}\right)$,

$$
\begin{aligned}
I_{3}\left(s_{\imath}\right)= & -t \sum_{\jmath=R+1}^{Q} p_{j} f\left(s_{i}-c_{\jmath}\right) \\
& +t \sum_{R<j(m)<Q}\left\{-d_{m} f\left(s_{i}-a_{m}\right)-e_{m} f\left(s_{\imath}-b_{m}\right)+\int_{E_{m}} f\left(s_{i}-u\right) k^{*}(u) d u\right\},
\end{aligned}
$$

$$
I_{4}\left(s_{\imath}\right)=t \int_{E_{q}} f\left(s_{i}-u\right) k^{*}(u) d u-t d_{q} f\left(s_{i}-a_{q}\right)-t e_{q} f\left(s_{i}-b_{q}\right)
$$

if $R<Q=j(q)(1 \leqq q \leqq n)\left(I_{4}\left(s_{\imath}\right)=0\right.$ if $Q \in J_{1}$ or $\left.R=Q\right)$,

$$
\begin{aligned}
I_{5}\left(s_{\imath}\right)= & -t \sum_{j=Q+1}^{N} p_{j} f\left(s_{i}-c_{j}\right) \\
& +t \sum_{J(m)>Q}\left\{-d_{m} f\left(s_{i}-a_{m}\right)-e_{m} f\left(s_{i}-b_{m}\right)+\int_{E_{m}} f\left(s_{i}-u\right) k^{*}(u) d u\right\} .
\end{aligned}
$$


We shall prove that

$$
\begin{aligned}
& I_{1}\left(s_{1}\right) \geqq\left(k\left(c_{R}+\right) t-1\right) f\left(s_{1}\right), \\
& I_{1}\left(s_{2}\right) \leqq\left(k\left(c_{R}+\right) t-1\right) f\left(s_{2}\right)
\end{aligned}
$$

(equality holds if and only if $R=0$ ),

and

$$
\begin{array}{ll}
I_{2}\left(s_{2}\right)<0 \quad \text { if } & R=j(r)(1 \leqq r \leqq n), \\
I_{2}\left(s_{2}\right)<I_{2}\left(s_{1}\right) \quad \text { if } \quad R=j(r)(1 \leqq r \leqq n), \\
I_{3}\left(s_{2}\right) \leqq 0, \\
I_{3}\left(s_{2}\right) \leqq I_{3}\left(s_{1}\right), & \\
I_{4}\left(s_{2}\right)<0 \quad \text { if } & R<Q=j(q)(1 \leqq q \leqq n), \\
I_{4}\left(s_{2}\right) \leqq I_{4}\left(s_{1}\right) \quad \text { if } \quad R<Q=j(q)(1 \leqq q \leqq n), \\
I_{5}\left(s_{1}\right)=0,
\end{array}
$$

These inequalities lead to a contradiction. In fact, we obtain from (3.36), (3.37), (3.39), (3.41), and (3.44) that

$$
0=I\left(s_{2}\right) \leqq I_{1}\left(s_{2}\right)<\left(t k\left(c_{R}+\right)-1\right) f\left(s_{2}\right)
$$

if $R \geqq 1$. Hence we have

$$
t k\left(c_{R}+\right)-1>0 \text {. }
$$

Note that this holds even for $R=0$. We find from (A.2), (3.35), (3.36), (3.38), (3.40), (3.42), (3.43), (3.44), and (3.46) that

$$
\begin{aligned}
0=I\left(s_{2}\right) & \leqq\left(t k\left(c_{R}+\right)-1\right) f\left(s_{2}\right)+I_{2}\left(s_{2}\right)+I_{3}\left(s_{2}\right)+I_{4}\left(s_{2}\right) \\
& <\left(t k\left(c_{R}+\right)-1\right) f\left(s_{1}\right)+I_{2}\left(s_{1}\right)+I_{3}\left(s_{1}\right)+I_{4}\left(s_{1}\right) \\
& \leqq I\left(s_{1}\right)=0 .
\end{aligned}
$$

This is a contradiction.

Now we prove the inequalities (3.35)-(3.44). We can prove (3.35) as in (2.18) of Lemma 2.6 and (3.36) as in (2.9) of Lemma 2.5. Also the proof of (2.9) shows that equality in (3.36) holds if and only if $R=0$, because $f(x)$ is strictly decreasing for $s_{1}<x<s_{2}$ by (A.2). We can prove (3.37) as in (3.21). To prove (3.38), we consider two possible cases.

(i) Suppose that $Q>R=j(r)(1 \leqq r \leqq n)$. Lemma 2.7 implies that 


$$
f\left(s_{2}-u\right)-f\left(s_{1}-u\right)<f\left(s_{2}-b_{r}\right)-f\left(s_{1}-b_{r}\right)
$$

for $s_{2}-s_{1}<u<b_{r}$ and

$$
f\left(s_{2}-u\right)-f\left(s_{1}-u\right) \leqq f\left(s_{1}\right)-f\left(s_{1}-u\right) \leqq f\left(s_{2}-b_{r}\right)-f\left(s_{1}-b_{r}\right)
$$

for $a_{r} \leqq u \leqq s_{2}-s_{1}$. Hence, noting $e_{r}>h_{r}$ we have that

$$
I_{2}\left(s_{2}\right)-I_{2}\left(s_{1}\right)<0 \text {, }
$$

which means (3.38).

(ii) Suppose that $Q=R=j(r)(1 \leqq r \leqq n)$. Then we note that $I_{2}\left(s_{1}\right)=$ $t \int_{E_{r}} f\left(s_{1}-u\right) k^{*}(u) d u \geqq 0$. Therefore, (3.38) follows from (3.37). Thus we have proved (3.38).

Since $f\left(s_{2}-u\right) \leqq f\left(s_{2}-a_{m}\right)$ for $u \in E_{m}(R<j(m)<Q)$, we get

$$
\begin{aligned}
I_{3}\left(s_{2}\right) & \leqq-t \sum_{j=R+1}^{Q} p_{j} f\left(s_{2}-c_{j}\right) \\
& -t \sum_{R<j(m)<Q}\left\{\left(d_{m}-h_{m}\right) f\left(s_{2}-a_{m}\right)+e_{m} f\left(s_{2}-b_{m}\right)\right\} \leqq 0,
\end{aligned}
$$

which implies (3.39). Since

$$
f\left(s_{2}-u\right)-f\left(s_{1}-u\right)<f\left(s_{2}-b_{m}\right)-f\left(s_{1}-b_{m}\right)
$$

for $u \in E_{m}(R<j(m)<Q)$ by Lemma 2.7 , we have

$$
\begin{array}{r}
\quad \int_{E_{m}} f\left(s_{2}-u\right) k^{*}(u) d u-e_{m} f\left(s_{2}-b_{m}\right) \\
<\int_{E_{m}} f\left(s_{1}-u\right) k^{*}(u) d u-e_{m} f\left(s_{1}-b_{m}\right)
\end{array}
$$

for $R<j(m)<Q$ as in (3.48). Hence (3.40) follows from $f\left(s_{2}-c_{\jmath}\right)>f\left(s_{1}-c_{\jmath}\right)$ for $R+1 \leqq j \leqq Q$. If $R<Q=j(q)(1 \leqq q \leqq n)$, then

$$
I_{4}\left(s_{2}\right) \leqq t\left(h_{q}-d_{q}\right) f\left(s_{2}-a_{q}\right)-t e_{q} f\left(s_{2}-b_{q}\right)<0,
$$

because $f\left(s_{2}-u\right) \leqq f\left(s_{2}-a_{q}\right)$ for $u \in E_{q}$. Thus we have proved (3.41). To prove (3.42), we consider two possible cases.

(i) Suppose that $s_{2}-a_{q} \geqq \alpha$. We get as in (3.21) that

$$
\begin{aligned}
& \int_{E_{q}} f\left(s_{2}-u\right) k^{*}(u) d u-e_{q} f\left(s_{2}-b_{q}\right)<f\left(s_{2}-a_{q}\right) h_{q}-e_{q} f\left(s_{2}-b_{q}\right) \\
& \leqq \frac{f\left(s_{2}-b_{q}\right)}{s_{2}-b_{q}}\left\{\left(s_{2}-a_{q}\right) h_{q}-\left(s_{2}-b_{q}\right) e_{q}\right\} \leqq \frac{f\left(s_{2}-b_{q}\right)}{s_{2}-b_{q}}\left\{\alpha\left(h_{q}-e_{q}\right)+\left(b_{q}-a_{q}\right) e_{q}\right\} \\
& \leqq 0 .
\end{aligned}
$$

Hence (3.42) follows from $f\left(s_{1}-b_{q}\right)=0$ and from $f\left(s_{2}-a_{q}\right)>f\left(s_{1}-a_{q}\right)$. 
(ii) Suppose that $\alpha>s_{2}-a_{q}$. Define

$$
G=\int_{E_{q}} f\left(s_{2}-u\right) k^{*}(u) d u-\int_{E_{q}} f\left(s_{1}-u\right) k^{*}(u) d u .
$$

We shall show that

$$
G \leqq \delta_{q}\left(s_{2}-s_{1}\right) f\left(s_{2}-a_{q}\right)
$$

We can write $G$ as

$$
G=\int_{D_{1}} f(u) k^{*}\left(s_{2}-u\right) d u-\int_{D_{2}} f(u) k^{*}\left(s_{1}-u\right) d u,
$$

where $D_{1}=\left(s_{2}-b_{q}, s_{2}-a_{q}\right)$ and $D_{2}=\left(0, s_{1}-a_{q}\right)$. If $s_{2}-b_{q} \leqq s_{1}-a_{q}$, then, by concavity of $k(u)$ on $E_{q}, k^{*}\left(s_{2}-u\right) \leqq k^{*}\left(s_{1}-u\right)$ for $s_{2}-b_{q}<u<s_{1}-a_{q}$, and hence, by (3.55),

$$
G \leqq \int_{D_{3}} f(u) k^{*}\left(s_{2}-u\right) d u \leqq \delta_{q}\left(s_{2}-s_{1}\right) f\left(s_{2}-a_{q}\right),
$$

where $D_{3}=\left(s_{1}-a_{q}, s_{2}-a_{q}\right)$. If $s_{2}-b_{q}>s_{1}-a_{q}$, then by (3.55),

$$
\begin{aligned}
G \leqq \int_{D_{1}} f(u) k^{*}\left(s_{2}-u\right) d u & \leqq \delta_{q}\left(b_{q}-a_{q}\right) f\left(s_{2}-a_{q}\right) \\
& <\delta_{q}\left(s_{2}-s_{1}\right) f\left(s_{2}-a_{q}\right) .
\end{aligned}
$$

Thus we have proved (3.54). We can show $d_{q} f^{\prime}\left(s_{2}-a_{q}\right)>\delta_{q} f\left(s_{2}-a_{q}\right)$ as in (2.35) of the proof of Lemma 2.7, using (ii) of Lemma 2.6 with $s_{1}=x$ and $s_{2}=y$. Hence we obtain from (3.54) and Lemma 2.7 that

$$
\begin{aligned}
I_{4}\left(s_{1}\right)-I_{4}\left(s_{2}\right) & \geqq t d_{q}\left(f\left(s_{2}-a_{q}\right)-f\left(s_{1}-a_{q}\right)\right)-t G \\
& >t\left(s_{2}-s_{1}\right)\left(d_{q} f^{\prime}\left(s_{2}-a_{q}\right)-\delta_{q} f\left(s_{2}-a_{q}\right)\right)>0,
\end{aligned}
$$

which means (3.42). The proof of (3.42) is complete.

The inequality (3.44) can be proved as in (3.28). This finishes the proof of (3.35)-(3.44). Thus the assertion (a) is established in Case A.

In Case $B$, we can prove the assertion (a) more simply. In fact, we can find $s_{1}$ and $s_{2}$ such that $0<s_{2}-s_{0}<c_{1}$ and $c_{Q} \leqq s_{0}<s_{1}<s_{2}<c_{Q+1}$ with $1 \leqq Q \leqq N$. For $i=1,2$, we obtain from (2.2) and (B.1) that

$$
0=s_{\imath} f^{\prime}\left(s_{\imath}\right)=I_{1}\left(s_{\imath}\right)+I_{2}\left(s_{\imath}\right),
$$

where

$$
\begin{aligned}
I_{1}\left(s_{i}\right)= & (\lambda t-1) f\left(s_{1}\right)-t \sum_{j=1}^{Q} p_{j} f\left(s_{i}-c_{j}\right) \\
& +t \sum_{j(m)<Q}\left\{-d_{m} f\left(s_{i}-a_{m}\right)-e_{m} f\left(s_{i}-b_{m}\right)+\int_{E_{m}} f\left(s_{i}-u\right) k^{*}(u) d u\right\},
\end{aligned}
$$


and

$$
I_{2}\left(s_{\imath}\right)=t \int_{E_{q}} f\left(s_{\imath}-u\right) k^{*}(u) d u-t d_{q} f\left(s_{i}-a_{q}\right)
$$

if $Q=j(q)(1 \leqq q \leqq n)\left(I_{2}\left(s_{\imath}\right)=0\right.$ if $\left.Q \in J_{1}\right)$. Since

$$
0<f\left(s_{2}-u\right)-f\left(s_{1}-u\right) \leqq f\left(s_{2}-b_{m}\right)-f\left(s_{1}-b_{m}\right)
$$

for $u \in E_{m}(j(m)<Q)$ by Lemma 2.7 , we have

$$
\begin{array}{r}
\quad \int_{E_{m}} f\left(s_{2}-u\right) k^{*}(u) d u-e_{m} f\left(s_{2}-b_{m}\right) \\
\leqq \\
\int_{E_{m}} f\left(s_{1}-u\right) k^{*}(u) d u-e_{m} f\left(s_{1}-b_{m}\right)
\end{array}
$$

for $j(m)<Q$ as in (3.48). Since $f\left(s_{1}\right) \geqq f\left(s_{2}\right)$ and $f\left(s_{2}-c_{j}\right)>f\left(s_{1}-c_{\jmath}\right)$ for $1 \leqq j \leqq Q$, we get by (3.62) that

$$
I_{1}\left(s_{1}\right)>I_{1}\left(s_{2}\right) .
$$

If $Q=j(q)(1 \leqq q \leqq n)$, then, choosing $s_{1}$ and $s_{2}$ sufficiently close to $s_{0}$, we have

$$
I_{2}\left(s_{1}\right) \geqq I_{2}\left(s_{2}\right)
$$

as in (3.42). Hence we obtain from (3.63) and (3.64) that

$$
0=I_{1}\left(s_{1}\right)+I_{2}\left(s_{1}\right)>I_{1}\left(s_{2}\right)+I_{2}\left(s_{2}\right)=0 .
$$

This is a contradiction. Thus the assertion (a) is true in Case B and the proof of Proposition 3.2 is complete.

Proof of Theorem 1.1. We divide the proof into three cases.

Case (I). $0<t \leqq \lambda^{-1}$. We find from Proposition 3.1 that $\mu_{t}$ is unimodal with mode 0, since (S.3.a) and (S.3.b) follow from (H.1), (H.2), and (H.3). In fact, we note by Remark 1.2 that $k\left(a_{m}+\right) \geqq 1 \geqq d_{m}$ for $1 \leqq m \leqq n$. Hence, (S.3.a) is true by (H.3.c). We obtain from (S.3.a) and from $\lambda^{-1} \leqq k(\alpha-)^{-1}$ that

$$
\begin{aligned}
& k\left(a_{m}+\right)\left(\lambda-k\left(a_{m}+\right)\right)-\delta_{m}\left(\lambda b_{m}-k\left(a_{m}+\right) a_{m}\right) \\
= & \lambda\left\{\lambda^{-1} k\left(a_{m}+\right)\left(\delta_{m} a_{m}-k\left(a_{m}+\right)\right)+k\left(a_{m}+\right)-\delta_{m} b_{m}\right\} \\
\geqq & \lambda k(\alpha-)^{-1}\left\{k\left(a_{m}+\right)\left(k(\alpha-)-k\left(a_{m}+\right)\right)-\delta_{m}\left(k(\alpha-) b_{m}-k\left(a_{m}+\right) a_{m}\right)\right\}
\end{aligned}
$$

for $1 \leqq m \leqq n$. We note by (H.1) and Remark 1.2 that, for $1 \leqq m \leqq n, 2 \geqq k(\alpha-)$ $\geqq k\left(a_{m}+\right) \geqq 1 \geqq d_{m}$ and hence

$$
k\left(a_{m}+\right)\left(k(\alpha-)-k\left(a_{m}+\right)\right) \geqq d_{m}\left(k(\alpha-)-k\left(b_{m}-\right)\right)
$$

and 


$$
\begin{aligned}
& k(\alpha-) a_{m}+\alpha k\left(b_{m}-\right)-\left(k(\alpha-) b_{m}-k\left(a_{m}+\right) a_{m}\right) \\
\geqq & \alpha\left(-k(\alpha-)+2 k\left(a_{m}+\right)\right) \geqq 0 .
\end{aligned}
$$

Now (S.3.b) follows from (3.66), (3.67), (3.68), and (H.3.c).

Case (II). $\quad \lambda^{-1}<t<1$. Proposition 3.2 shows the unimodality of $\mu_{t}$ in this case, because $1 \leqq 2 \lambda^{-1}$ by (H.1).

Case (III). $t \geqq 1$. Let $\phi_{1}(x)=h(x)$ and $\phi_{2}(x)=g(x)$. For $i=1,2$ define onesided Lévy processes $\left\{X_{t}^{(i)}\right\}$ with the distribution $\mu_{t}^{(i)}$ such that

$$
\begin{aligned}
& E \exp \left(-z X_{t}^{(i)}\right)=\exp \left(t \phi_{i}(z)\right), \\
& \phi_{i}(z)=\int_{0}^{\infty}\left(e^{-z x}-1\right) x^{-1} \phi_{i}(x) d x .
\end{aligned}
$$

Then we find from (H.2) that the process $\left\{X_{t}^{(1)}\right\}$ is of class $L$ and hence unimodal by Wolfe [12], and that $\mu_{t}^{(2)}$ is strongly unimodal for $t \geqq 1$ by Yamazato's theorem [15]. Hence $\mu_{t}=\mu_{t}^{(1)} * \mu_{t}^{(2)}$ is unimodal for $t \geqq 1$. The proof of Theorem 1.1 is complete.

\section{REFERENCES}

[1] Medgyessy, P., On a new class of unimodal infinitely divisible distribution functions and related topics, Studia Sci. Math. Hungar., 2 (1967), 441-446.

[2] SATO, K., Bounds of modes and unimodal processes with independent increments, Nagoya Math. J. 104 (1986), 29-42.

[3] SATO, K., Behavior of modes of a class of processes with independent increments, J. Math. Soc. Japan, 38 (1986), 679-695.

[4] Sato, K. and Yamazato, M., On distribution functions of class L, Z. Wahrsch. verw. Gebiete, 43 (1978), 273-308.

[5] Steutel, F. W., On the zeros of infinitely divisible densities, Ann. Math. Statist., 42 (1971), 812-815.

[6] Steutel, F.W. And van Harn, K., Discrete analogues of self-decomposability and stability, Ann. Probability, 7 (1979), 893-899.

[7] Tucker, H.G., Absolute continuity of infinitely divisible distributions, Pacific J. Math., 12 (1962), 1125-1129.

[8] Watanabe, T., Non-symmetric unimodal Lévy processes that are not of class L, Japan. J. Math., 15 (1989), 191-203.

[9] Watanabe, T., On the strong unimodality of Lévy processes, Nagoya Math. J., 121 (1991), 195-199.

[10] WatanaBE, T., On unimodal Lévy processes on the nonnegative integers, preprint.

[11] Watanabe, T., On Yamazato's property of unimodal one-sided Lévy processes, preprint.

[12] Wolfe, S. J., On the unimodality of L functions, Ann. Math. Statist., 42 (1971), 912-918.

[13] Wolfe, S.J., On the unimodality of infinitely divisible distribution functions, $Z$. Wahrsch. verw. Gebiete, 45 (1978), 329-335. 
[14] Yamazato, M., Unimodality of infinitely divisible distribution functions of class L, Ann. Probability, 6 (1978), 523-531.

[15] Yamazato, M., On strongly unimodal infinitely divisible distributions, Ann. Probability, 10 (1982), 589-601.

NAKAMANDOKORO

AizUBANGEMACHI

FuKUSHIMAKEN, 969-65

JAPAN 